\title{
HISTORIA SOCIAL DE LA EDUCACIÓN EN CIENCIAS E HISTORIA SOCIAL DE LAS CIENCIAS. SEGUNDA MITAD DEL SIGLO XX: UNA CONTRASTACIÓN
}

\author{
The social history of science education \\ in the second half of XX century
}

\author{
Rómulo Gallego Badillo ${ }^{1}$ • Adriana Patricia Gallego Torres ${ }^{2}$ • \\ Royman Pérez Miranda ${ }^{1}$ • Roberto Figueroa Molina ${ }^{3}$
}

Resumen: Este artículo se desprende de un proyecto de investigación realizada durante 2008 y 2009. Se presentan los resultados finales obtenidos con una entrevista practicada a directivos, profesores y egresados de los programas de formación inicial de profesores de ciencias de siete universidades oficiales de Colombia. Se contrastó la hipótesis de que la historia social de la educación en ciencias de un país, está ligada a la historia social de las ciencias en ese país. Se caracterizó la concepción de ciencia dominante en la segunda mitad del siglo XX en esos programas de formación inicial. Se revisaron los acontecimientos culturales, políticos, económicos, científicos y tecnológicos mundiales más significativos durante ese periodo y sus efectos en el país. Prevaleció una tradición cultural, una historia interna y externa que hicieron que la educación en ciencias continuara siendo la habitual.

Palabras clave: Enseñanza de la ciencia. Epistemología. Cultura. Historia. Tecnología didáctica y pedagogía.

\begin{abstract}
This article emerges from a research project carried out during 2008 and 2009. It presents the final results obtained from an interview applied to administrators, teachers and graduates of education programs for science teachers at seven public universities in Colombia. We compared the hypothesis that the social history of science education in a country is linked to the social history of science in that country. We have characterized the dominant conception of science in the second half of the twentieth century in these education programs. The authors reviewed the most relevant cultural, political, economic, scientific and technological events around the world during this period and their effects on the country. It was found that the prevailing cultural tradition, the internal and external history that made science education, continues to be the same.
\end{abstract}

Keywords: Science education. Epistemology. Culture. History. Didatics technology and pedagogy.

\footnotetext{
${ }^{1}$ Universidad Pedagógica Nacional, Bogotá, D. C. Colombia. Calle 72, n. 11-86, Edifico B, Cuarto Piso, Bogotá, Colombia. E-mail: rgallego@pedagogica.edu.co

${ }^{2}$ Universidad Distrital Francisco José de Caldas, Bogotá, D. C. Colombia.

${ }^{3}$ Universidad del Atlántico, Barranquilla, Colombia.
} 


\section{Introducción}

El proyecto se inició con la formulación de que la introducción de la historia de las ciencias en la enseñanza de las ciencias mejora la comprensión sobre la construcción de los conceptos y teorías de las ciencias (MATTHEWS, 1994). La pregunta que emergió fue ¿Desde cuál historia? T. S. Kuhn (1972) puntualizó que todo análisis epistemológico tenían necesariamente que estar históricamente fundamentado, no sobre suposiciones sino en la revisión de los documentos originales en los que cada comunidad científica puso en circulación sus propuestas innovadoras. I. Lakatos (1983) en la década de los setenta, estipuló que toda reconstrucción histórica estaba epistemológicamente comprometida, Es decir, cada evento científico significativo que fuera convertido en hecho histórico, sería interpretado desde el positivismo o enmarcado en las aproximaciones del cambio científico (ESTANY, 2005), es decir, desde las miradas deductivistas. Así, en la sustitución de teorías (POPPER, 1962), en el cambio de paradigmas o en la del abandono de programas de investigación.

El libro del profesor K. Popper, "Logik der Fosrschun" fue publicado en 1936, su versión en inglés en 1955 y la castellana, salvo mejor información, hasta 1962. Año este en el que T. S. Kuhn pone a circular "The scientific revolution", que fue traducido al castellano en 1972. Esta información es relevante cuando se emprende la revisión de la concepción de ciencia dentro de la cual se inscribieron los programas académicos para la formación de profesores de ciencias en Colombia, a lo largo de la segunda mitad del siglo XX. No obstante, es preciso destacar que en el país a finales del siglo XIX se prohibió cualquier mención y discusión sobre la aproximación epistemológica positivista. Fue impuesto oficialmente la filosofía conocida como "Neotomismo" (JARAMILLO, 1986).

Frente a la pluralidad de las reconstrucciones históricas el problema que se formuló fue el de la credibilidad. Una respuesta que se ha ensayado ha sido el de la revisión crítica de las fuentes en las que se sostiene cada una de estas versiones y, por supuesto, el apoyó en los artículos originales publicados en las revistas especializadas. Las fuentes primarias (JENKINS, 2006). Una vez constatadas la veracidad de estas fuentes y sus lecturas críticas, el problema se trasladó a determinar hasta dónde las correspondientes interpretaciones eran aceptables. En cuanto a las reconstrucciones positivistas, los especialistas han anotado que han puesto en circulación la idea de que el conocimiento científico ha obedecido ha una sucesión lineal de descubrimientos por aplicación del denominado método científico único, cuyos fundamentos fueron desmontados primero, por K. Popper y después por los historiadores de las ciencias y epistemólogos (ZAHAR, 1980).

En esa versión no se suelen considerar los problemas de conocimiento que dieron origen a cada una de las propuestas innovadoras, las distintas soluciones que estuvieron en competencia y las razones por las cuales una de ellas terminó por ser admitida por cada comunidad de especialistas. Se deja de lado el hecho de que cada una de estas comunidades tuvo que hacer replanteamiento y rectificaciones de sus presupuestos conceptuales y metodológicos iniciales (STENGER, 1989). Se divulgó a través de los sistemas educativos la idea de que cada una de las ciencias ha sido construida históricamente por individuos geniales (GALLEGO TORRES, 2002).

La siguiente reflexión apuntó a la historia social de las ciencias o historia externa de las ciencias. Estos estudios se inician en 1932 (MUMFORD, 2006). Luego continúan con las 
dos investigaciones de K. Merton de 1938 y 1949 que versaron sobre el desarrollo de las ciencias en la Inglaterra del siglo XVII (BARONA, 1994), cuyos fundamentos han sido objeto de controversias (BARNES; DOLBY, 1995). No obstante, algunos autores remontan estos inicios a F. Bacon (MULKAY, 1995). Los resultados han demostrado el papel significativo cumplido por el contexto social, cultural, político y económico en el desarrollo del conocimiento científico (RESTIVO, 1992; VESSURI, 1992) y de la actividad científica (ECHEVARRÍA, 1955); actividad que se identifica como sistema de producción (BERNAL, 1976). La institucionalización de la actividad científica hizo necesario involucrar a la sociedad (BOWLER; MORUS, 2007). La búsqueda del apoyo social fue el origen de una educación científica para todos (COLLINS; PINCH, 2006; DICKSON, 2000). Es preciso diferenciar los estudios sociales de los etnográficos (KNORR-CETINA, 1995; LATOUR; WOOLGAR, 1995). Estos últimos no fueron el propósito del proyecto de investigación.

Hay que señalar la controversia que se estableció entre historiadores "internalistas" y "externalistas" de las ciencias, que fue zanjada por T. S. Kuhn (1972) con el texto ya referenciado (SHAPIN, 2005). Se concluirá que las dos son complementarias si se quiere reconstruir una versión completa de la historia del desarrollo del conocimiento científico. Todo esto dentro de la concepción de pluralidad histórica (ESTANY, 2005), pluralidad de ciencias y pluralidad metodológica. Las consecuencias de estas revisiones fueron que reconstruir una historia social de la educación en ciencias tenía necesariamente que ocuparse de la correspondiente reconstrucción interna, es decir, de la concepción de ciencia que estuvo en la base de los programas académicos de formación inicial de profesores de ciencias en Colombia en el período demarcado.

\section{La educación en ciencias}

Se habla de "educación en ciencias" (COLLINS; PINCH, 2006) y no de "educación científica"; la primera alude a la aproximación del alumnado de la cultura científico-tecnológica; la segunda a la formación científica propiamente dicha. Puesto que los pedagogos han delimitado su campo de trabajo con la categoría de educación, surgieron interrogantes en el grupo ¿Educan las ciencias?, ¿cuál es el carácter educativo de estas?, ¿en qué radica la educabilidad que se pretende propiciar con la conversión de la actividad científica de los colectivos especializados en ciencia escolar? y ¿de qué manera esa conversión se encuentra influenciada por la historia y los intereses políticos y económicos que dirigen los proyectos educativos de cada nación y sus gobiernos? Al respecto no se encontraron trabajos que permitieran adelantar aproximaciones discutibles.

\section{La didáctica de las ciencias}

Las propuestas popperianas y kuhnianas condujeron a un grupo de personajes formados en ciencias, a preguntarse por la versión de ciencia que se hacía objeto de trabajo en el aula. La enfrentaron como un problema de investigación cuyos resultados fueron la formulación de una distinta didáctica de las ciencias. Ella rompió con esa reducción de ser la parte 
Badillo, R. G. et al.

instrumental de la pedagogía. Adoptaron algunos de estos investigadores la aproximación constructivista (NOVAK, 1988). Se formuló el concepto de aprendizaje significativo (AUSUBEL; NOVAK; HANESIAN, 1983). Este se expresó en la elaboración de mapas conceptuales y en la uve heurística (NOVAK; GOWIN, 1984). Rompió con el memorístico puesto que el estudiantado no incorporaba mecánicamente a su estructura conceptual los contenidos presentados por el profesorado (MOREIRA, 1990).

Desde compromisos epistemológicos explícitos, se elaboraron otras propuesta. La del aprendizaje como cambio conceptual (POSNER et al., 1982), la del cambio conceptual y metodológico (GIL PÉREZ; CARRASCOSA ALIS, 1985). La del cambio conceptual, metodológico y actitudinal (GENÉ, 1991); y la del cambio conceptual, metodológico, actitudinal y axiológico, del que se ha sostenido que obedece a la lógica de la no linealidad (GALLEGO BADILLO et al., 2004). Estas propuestas implicaron la necesidad de enfrentar la enseñanza a partir de estrategias diferentes a las habituales.

Un nuevo campo de investigación fue el de la confiabilidad de los textos de enseñanza. Los que con él se comprometieron, retomaron la propuesta de los especialistas franceses en educación matemática sobre la transposición didáctica (CHEVALLARD, 1985). En consecuencia, dentro de este retomar, se realizaron proyectos de investigación puntuales (CAMACHO GONZÁLEZ; GALLEGO BADILLO; PÉREZ MIRANDA, 2007; CUELLAR FERNÁNDEZ; GALLEGO BADILLO; PÉREZ MIRANDA, 2008; GÁNDARA GÓMEZ; GIL QUÍLEZ; SANMARTÍ PUIG, 2002). Los resultados hablan en favor de que los textos analizados contienen errores conceptuales, además de socializar unos contenidos descontextualizados y ahistóricos.

\section{Las relaciones entre las ciencias y las tecnologías}

Esta se inicia con Galileo y su construcción del experimento en física, puesto que la nueva ciencia que crea es instrumental, tecnológica. Acudiendo a los historiadores sociales de la actividad científica que se inicia en el siglo XVII, que se fue concretando paulatinamente con el diseño y construcción de máquinas herramientas en la conquista de la precisión. Se requirió de un tiempo para esa complementación entre las ciencias y las tecnologías (GALLEGO TORRES; MONTENEGRO MARÍN; GALLEGO BADILLO, 2012).

Desde la esta perspectiva, existe una estrecha relación entre cada una de las ciencias y las diferentes tecnologías. Dicha relación hará que la pregunta por la confiabilidad de los datos experimentales esté siempre en la preocupación de las comunidades de especialistas. El concepto central de esa confiabilidad es el de precisión en relación con el matemático de exactitud. Los tecnólogos harán de su contribución a las ciencias, el diseño y fabricación de instrumentos de mayor precisión (WEIGHTMAN, 2008).

No obstante, en los comienzos de la revolución científica del siglo XVII, las publicaciones desconocieron el papel desempeñado por los constructores de instrumentos en la obtención de resultados (BOWLER; MORUS, 2007; SÁNCHEZ, 2009). Aún cuando ya hacia mediados de 1776, una media docena de constructores de instrumentos científicos son admitidos como miembros de la "Royal Society" (DERRY; WILLIAMS, 1977). Señálese además que las explicaciones sobre las condiciones que coadyuvaron la "revolución científica" del siglo XVII, traen a colación la relación entre actividad tecnológica y producción industrial. 
Historia social de la educación ...

\section{Del problema}

Este se formuló como sigue ¿Cuál fue la incidencia efectiva que tuvieron las nuevas elaboraciones histórico-epistemológicas en la formación inicial de profesores de ciencias en Colombia?, ¿De qué manera efectiva incidió el contexto social, político y económico colombiano de la segunda mitad del siglo XX en esa formación? y ¿Hasta donde es posible elaborar una historia externa e interna de la educación en ciencias?

\section{Aspectos metodológicos}

La metodología adoptada, es la investigación descriptiva, que consiste en llegar a conocer las situaciones, costumbres y actitudes predominantes, a través de la descripción exacta de las actividades, objetos, procesos y personas. Su meta no se limita a la recolección de datos, a la caracterización e identificación de las relaciones que existen entre las diferentes variables. Se caracteriza también, por realizar un esfuerzo importante por articular los diferentes componentes del proyecto con el propósito principal de responder de forma compleja al problema de investigación, a partir del cumplimiento de los objetivos desde una perspectiva teórica particular.

En concordancia con los objetivos de la investigación, se entrevistaron directivos, profesores y egresados de los programas de formación inicial de profesores de ciencias de las universidades: Universidad Pedagógica Nacional (UPN), de Bogotá; Universidad Distrital Francisco Jose de Caldas (UDFJC), de Bogotá; Universidad Pedagógica y Tecnológica de Colombia (UPTC), de la ciudad de Tunja; Universidad del Atlántico, de Barranquilla; Universidad del Valle (UNIVALLE), de Cali; Universidad Tecnológica del Chocó, Quibdó, (UTCH) y Universidad del Cauca, Popayán (UCAUCA). Para tal efecto, se diseñó una entrevista semiestructurada cuyos interrogantes iniciales fueron sometidos a revisión por parte de pares académicos. Del análisis crítico de las sugerencias, se tomó la decisión por las siguientes:

- ¿Cómo ha sido o fue la enseñanza de las ciencias en el programa (EC)?

- ¿De que manera esa enseñanza fue enfocada desde la historia de las ciencias (HC)?

- ¿Qué relación se trabajo con las tecnologías (CT)?

- ¿Qué puede decir con respecto a los textos de enseñanza recomendados por los profesores del programa (TE)?

- ¿Cómo incidió la formación recibida en su desempeño profesional (FP)?

Para dar cuenta del segundo interrogante del problema, se procedió a caracterizar los hechos culturales, sociales, políticos, científicos y tecnológicos más sobresalientes acaecidos en el mundo durante esa segunda mitad del siglo XX y sus consecuencias en el desarrollo científico, tecnológico y de la educación en ciencias en Colombia. Se tipificaron los convenios internacionales que en el campo del desarrollo científico y tecnológico los diferentes gobiernos establecieron. Se analizaron las Leyes y Decretos que se expidieron en relación con la educación en general y con la formación inicial y continua de profesores de ciencias. 
Badillo, R. G. et al.

\section{Análisis de resultados}

El diseño metodológico incluyó entrevistas semiestructuradas, análisis documental y triangulación con expertos, hemos considerado que las encuestas son el instrumento que más representa la resolución del problema, en esta ocasión y dada la necesidad de sintetizar el proyecto, los resultados que aquí presentamos hacen referencia a las entrevistas realizadas con directores y profesores actuales de los programas de cada una de las universidades mencionadas anteriormente y a egresados de esos programas, en las fechas que se anotan, Así:

\section{Universidad Pedagógica y Tecnológica de Colombia (UPTC)}

Para una acertada comprensión de los resultados, es preciso aclarar que la UPTC nace como consecuencia de la supresión por motivaciones políticas, de la Escuela Normal Superior de Colombia (ENSC), inicialmente como Escuela Normal Universitaria para Varones de Tunja (la Capital del Departamento de Boyaca), luego recibió el nombre de Universidad Pedagógica de Colombia, que conservo de su origen la formación inicial de profesores de ciencias, en los programas de Licenciatura en Biología y Química y en Física y Matemáticas. Estos programas fueron eliminados, de tal manera que se formuló el de "Licenciatura en Educación Básica, con Énfasis en Ciencias Naturales y Educación Ambiental”. El director, los profesores y los egresados, se formaron en los programas anteriores.

Como puede destacarse en el Cuadro 1, tanto el director, los tres profesores y los siete egresados, frente a la pregunta de cómo había la enseñanza de las ciencias (EC) desde 1966 hasta 1991, las respuestas obtenidas coincidieron en que había sido la habitual, esto es, caracterizada por la transmisión verbal de contenidos curriculares. En cuanto a si esa EC se había centrado o se había hecho alusión a la historia (HC) de cada una de las unidades didácticas trabajadas en el aula, todos los entrevistados respondieron que no. Cuando se interrogó por cómo se había tocado el tema de las relaciones entre ciencia y tecnología (CT), solo el director

Cuadro 1. Respuestas de los entrevistados.

\begin{tabular}{|l|c|c|c|c|c|}
\hline & EC & HC & CT & TE & FP \\
\hline Dirct & $\mathrm{H}$ & $\mathrm{N}$ & $\mathrm{I}$ & $\mathrm{H}$ & $\mathrm{H}$ \\
\hline Prof1 & $\mathrm{H}$ & $\mathrm{N}$ & $\mathrm{N}$ & $\mathrm{PCr}$ & $\mathrm{H}$ \\
\hline Prof2 & $\mathrm{H}$ & $\mathrm{N}$ & $\mathrm{N}$ & $\mathrm{H}$ & $\mathrm{H}$ \\
\hline Prof3 & $\mathrm{H}$ & $\mathrm{N}$ & $\mathrm{N}$ & $\mathrm{H}$ & $\mathrm{H}$ \\
\hline Egr66 & $\mathrm{H}$ & $\mathrm{N}$ & $\mathrm{N}$ & $\mathrm{H}$ & $\mathrm{H}$ \\
\hline Egr79 & $\mathrm{H}$ & $\mathrm{N}$ & $\mathrm{N}$ & $\mathrm{H}$ & $\mathrm{H}$ \\
\hline Egr81 & $\mathrm{H}$ & $\mathrm{N}$ & $\mathrm{N}$ & $\mathrm{H}$ & $\mathrm{PCr}$ \\
\hline Egr86 & $\mathrm{H}$ & $\mathrm{N}$ & $\mathrm{N}$ & $\mathrm{H}$ & $\mathrm{H}$ \\
\hline Egr88 & $\mathrm{H}$ & $\mathrm{N}$ & $\mathrm{N}$ & $\mathrm{H}$ & $\mathrm{PCr}$ \\
\hline Egr89 & $\mathrm{H}$ & $\mathrm{N}$ & $\mathrm{N}$ & $\mathrm{H}$ & $\mathrm{H}$ \\
\hline Egr91 & $\mathrm{H}$ & $\mathrm{N}$ & $\mathrm{N}$ & $\mathrm{H}$ & $\mathrm{PCr}$ \\
\hline
\end{tabular}

Fuente: elaborado por los autores. 
Historia social de la educación ...

del programa actual hizo referencia a la Informática (I), mientras que el resto de los entrevistados optaron por la respuesta negativa. En lo concerniente a la pregunta acerca de cuál era la posición crítica que tenían frente a los textos de enseñanza (TE) recomendados o usados por los profesores cuando estaban cursando el programa o si, en virtud de que se estaban formando inicialmente como profesores de ciencias se les había dado la oportunidad de elaborar una posición crítica frente a tales textos, con la excepción del profesor 1, los demás respondieron de manera negativa, por lo que los responsables del proyecto de investigación resolvieron calificarla como la habitual $(\mathbf{H})$, esto es los textos se admitieron sencillamente porque eran los recomendado por cada uno de los profesores. Frente al interrogante de cómo había incidido en su formación profesional (FP) como profesores de ciencias, los egresados de 1981, 1988 y 1981, asumieron una posición crítica (PCr.). Los otros entrevistados se inclinaron por subrayar que fue la esperada de conformidad con los objetivos del respectivo programa de formación; por esta razón se calificaron como habituales $(\mathbf{H})$.

\section{La Universidad Pedagógica Nacional (UPN)}

\section{Licenciatura en Química}

De todas las respuestas obtenidas de directivos, profesores y egresados de los programas académicos de formación de profesores de ciencias, 12 programas un total de 36 profesores de los distintos programas, con excepción de la Universidad del Valle y de la Universidad del Atlántico, dado que en esos programas la enseñanza de las ciencias corría a cargo de profesores de las respectivas facultades de ciencias que no fueron objeto de entrevista y de cinco egresados en promedio, esto es sesenta.

De la clasificación que se hizo de las cuatrocientas veinte respuestas, en general, 27 del total caen en la categoría de no habitual (NH). Desde la misma contabilidad se obtuvo, con algunas excepciones, que en estos programas la enseñanza de las ciencias (EC) no estuvo mediada por una aproximación histórica, como tampoco por la relación igualmente histórica entre cada una de las ciencias y las tecnologías correspondientes. (CT). Predominó durante la segunda mitad del siglo XX la versión habitual de la actividad científica anterior a los cambios de miradas introducidos por las aproximaciones histórico-epistemológicas que se propusieron y que fundamentaron este proyecto de investigación. Por tanto, se puede afirmar que siguió predominando, en la versión de ciencia que se hizo objeto de enseñanza, la de que cada una de estas ciencias carecía de historia (ver Cuadro 2. Programa UPN A).

En lo tocante a las relaciones entre ciencia y tecnología (CT), la ausencia de una enseñanza mediada por la historia $(\mathrm{CH})$ posiblemente es la causa del desconocimiento de que es Galileo el creador de una nueva ciencia de carácter instrumental en el caso de la física, y de que en la química A. L. Lavoisier introdujera la balanza como instrumento para redefinir cuantitativamente el concepto de reacción química y, por tanto, formular la ley de la conservación de los pesos. De la misma manera, el papel del microscopio en los inicios de la biología como ciencia, debido a M. Malpighi (1628-1694). 
Badillo, R. G. et al.

\section{Programa A}

\section{Cuadro 2. Resultados obtenidos con directivos, profesores y egresados} de este programa.

\begin{tabular}{|l|c|c|c|c|c|}
\hline & EC & HC & CT & TE & FP \\
\hline Dirct & PCr & N & N & H & H \\
\hline Prof1 & H & N & N & H & H \\
\hline Prof2 & H & N & I & H & H \\
\hline Prof3 & H & N & I & H & NH \\
\hline Egr59 & H & N & N & H & H \\
\hline Egr71 & $\mathrm{H}$ & $\mathrm{N}$ & $\mathrm{N}$ & $\mathrm{PCr}$ & $\mathrm{H}$ \\
\hline Egr72 & $\mathrm{H}$ & $\mathrm{N}$ & $\mathrm{N}$ & $\mathrm{H}$ & $\mathrm{H}$ \\
\hline Egr74 & $\mathrm{H}$ & $\mathrm{N}$ & $\mathrm{N}$ & $\mathrm{H}$ & $\mathrm{H}$ \\
\hline Egr68 & $\mathrm{H}$ & $\mathrm{N}$ & $\mathrm{N}$ & $\mathrm{H}$ & $\mathrm{H}$ \\
\hline Egr82 & $\mathrm{H}$ & $\mathrm{N}$ & $\mathrm{N}$ & $\mathrm{H}$ & $\mathrm{H}$ \\
\hline Egr86 & $\mathrm{H}$ & $\mathrm{N}$ & $\mathrm{N}$ & $\mathrm{H}$ & $\mathrm{H}$ \\
\hline Egr88 & $\mathrm{H}$ & $\mathrm{N}$ & $\mathrm{H}$ & $\mathrm{H}$ & $\mathrm{H}$ \\
\hline Egr88' & $\mathrm{H}$ & $\mathrm{N}$ & $\mathrm{N}$ & $\mathrm{PCr}$ & $\mathrm{PCr}$ \\
\hline Egr91 & $\mathrm{H}$ & $\mathrm{N}$ & $\mathrm{N}$ & $\mathrm{PCr}$ & $\mathrm{PCr}$ \\
\hline Egr93 & $\mathrm{H}$ & $\mathrm{N}$ & $\mathrm{N}$ & $\mathrm{PCr}$ & $\mathrm{H}$ \\
\hline Egr94 & $\mathrm{H}$ & $\mathrm{N}$ & $\mathrm{N}$ & $\mathrm{H}$ & $\mathrm{PCr}$ \\
\hline Egr94' & $\mathrm{H}$ & $\mathrm{N}$ & $\mathrm{I}$ & $\mathrm{H}$ & $\mathrm{H}$ \\
\hline
\end{tabular}

Fuente: elaborado por los autores.

En lo tocante a los textos de enseñanza (TE), si bien hubo algunos profesores que manifestaron al respecto una posición crítica (PCr), las respuestas clasificadas como habitual $(\mathrm{H})$ dan a entender que la socialización de las ciencias en Colombia siguió sometida a la transmisión de los contenidos presentados en los textos de enseñanza; un uso acrítico de la aceptación de esos contenidos, sobre todo en los programas académicos de formación de profesores de ciencias. Puesto que en ninguna de las respuestas que se dieron a la pregunta relativa a los TE, las revistas especializadas en las que se publicaron los modelos científicos objeto de enseñanza no fueron aludidas, es admisible especificar que la idea de ciencia que se transmitió fue la "didactizada" contenida en esos libros de texto (ver Cuadros 3 y 4. Programa UPN B y C). 
Historia social de la educación ...

\section{Programa B de la UPN}

Cuadro 3. Resultados obtenidos con directivos, profesores y egresados de este programa.

\begin{tabular}{|l|c|c|c|c|c|}
\hline & EC & HC & CT & TE & FP \\
\hline Dirct & H & NH & NH & NH & H \\
\hline Prpf2 & PCr & NH & N & H & H \\
\hline Prof2 & $\mathrm{NH}$ & $\mathrm{NH}$ & $\mathrm{N}$ & $\mathrm{PCr}$ & $\mathrm{PCr}$ \\
\hline Prof3 & $\mathrm{H}$ & $\mathrm{H}$ & $\mathrm{H}$ & $\mathrm{H}$ & $\mathrm{H}$ \\
\hline Egr75 & $\mathrm{H}$ & $\mathrm{N}$ & $\mathrm{N}$ & $\mathrm{H}$ & $\mathrm{NH}$ \\
\hline Egr78 & $\mathrm{H}$ & $\mathrm{N}$ & $\mathrm{N}$ & $\mathrm{H}$ & $\mathrm{H}$ \\
\hline Egr84 & $\mathrm{H}$ & $\mathrm{H}$ & $\mathrm{N}$ & $\mathrm{H}$ & $\mathrm{H}$ \\
\hline Egr89 & $\mathrm{H}$ & $\mathrm{NH}$ & $\mathrm{N}$ & $\mathrm{H}$ & $\mathrm{H}$ \\
\hline
\end{tabular}

Fuente: elaborado por los autores.

\section{Programa C de la UPN}

Cuadro 4. Resultados obtenidos con directivos, profesores y egresados de este programa.

\begin{tabular}{|l|c|c|c|c|c|}
\hline & EC & HC & CT & TE & FP \\
\hline Dirct & $\mathrm{NH}$ & $\mathrm{NH}$ & $\mathrm{NH}$ & $\mathrm{PCr}$ & $\mathrm{NH}$ \\
\hline Prof1 & $\mathrm{NH}$ & $\mathrm{NH}$ & $\mathrm{NH}$ & $\mathrm{H}$ & $\mathrm{NH}$ \\
\hline Prof2 & $\mathrm{NH}$ & $\mathrm{N}$ & $\mathrm{N}$ & $\mathrm{H}$ & $\mathrm{H}$ \\
\hline Egr75 & $\mathrm{H}$ & $\mathrm{N}$ & $\mathrm{H}$ & $\mathrm{H}$ & $\mathrm{H}$ \\
\hline Egr75, & $\mathrm{H}$ & $\mathrm{H}$ & $\mathrm{N}$ & $\mathrm{H}$ & $\mathrm{PCr}$ \\
\hline Egr81 & $\mathrm{H}$ & $\mathrm{N}$ & $\mathrm{N}$ & $\mathrm{N}$ & $\mathrm{H}$ \\
\hline Egr87 & $\mathrm{H}$ & $\mathrm{H}$ & $\mathrm{N}$ & $\mathrm{H}$ & $\mathrm{H}$ \\
\hline Egr89 & $\mathrm{H}$ & $\mathrm{NH}$ & $\mathrm{N}$ & $\mathrm{H}$ & $\mathrm{NH}$ \\
\hline Egr97 & $\mathrm{H}$ & $\mathrm{H}$ & $\mathrm{N}$ & $\mathrm{H}$ & $\mathrm{H}$ \\
\hline
\end{tabular}

Fuente: elaborado por los autores.

\section{Conclusiones}

Estas se expresan a través de los siguientes aspectos: En lo tocante a la formación inicial de profesores de ciencias en los programas académicos trabajados, con las también excepciones destacables, la ausencia de un tratamiento histórico desde la historia y la falta de una mirada de las ciencias en relación con las tecnologías, sugiere igualmente el predominio de la aproximación epistemológica positivista. $\mathrm{Ni}$ en las respuestas de los directivos de los programas académicos, ni en las de los egresados se hizo alusión a la historia social de las ciencias. De esta manera, los contenidos de las asignaturas de ciencia que se transmitieron en esos programas, más que tergiversados se presentaron descontextualizados. 
Un análisis del predominio, tanto en las respuestas de la mayoría de los directivos y profesores de ciencias, como de los egresados de los programas académicos para la formación inicial de profesores de ciencias de las Facultades de Educación, con respecto a los textos de enseñanza, permiten colegir, en primer lugar, que la versión de ciencia que se transmitió fue la contenida en los textos de enseñanza, esto es, "una ciencia producto". En segundo lugar, llama la atención que siendo estos textos uno de los apoyos preponderantes a los que se acude el profesorado de ciencias para su desempeño profesional, en dichos programas esos textos se siguieran de manera acrítica y no fueran objeto de análisis sobre la confiabilidad epistemológica e histórica de sus contenidos.

Sobre los textos de enseñanza de las ciencias en las Facultades de Educación, llama la atención que los directivos, profesores y egresados entrevistados no hayan hecho alusión alguna la utilización, tan esporádica como se quiera, de las revistas especializadas en ciencias. Hay que insistir en que la formación inicial de profesores de ciencias en los programas académicos de las Facultades de Educación, con los propósitos supuestos de que los países en vía de desarrollo se vincularan al proceso de desarrollo científico y tecnológico, en el plano de la Guerra Fría, no paso de ser una capacitación teórica e irrealizable en sus países de orígenes, que no contaban con la historia de producción de conocimiento científico, pero que podrían constituirse en colaboradores, contrastadores de las razones por las cuales en Colombia la clase de versión de ciencias que se transmitió a los profesores en formación inicial, en esos programas académicos.

Extrapolando los resultados obtenidos y aún cuando resultare una apreciación criticable, no resulta descabellado sostener que el dominio de la aproximación positivista en esa versión de ciencia, estuvo marcada por una habitualidad implementada por esos textos de uso y, en consecuencia por la no necesidad de un análisis filosófico, cultural, político y económico de esa aproximación que se admitía y se transmitía sin más. Las respuestas obtenidas dan pie para pensar, en primer lugar, que la enseñanza de las ciencias en esos programas no obedeció, en principio a una teoría pedagógica o a una teoría didáctica acerca de la enseñanza de las ciencias. La enseñanza siguió las concepciones habituales.

A pesar de que el incremento de las investigaciones científico-tecnológicas y sus productos comenzaron a incidir en las relaciones entre las personas y de que hubo convenios con organismos internacionales, estos hechos no incidieron en las transformaciones de la educación en ciencias en el país, como tampoco contribuyó significativamente a la institucionalización de la ciencia en Colombia, generando en la población una cultura científico-tecnológica diferente entre ella.

Con los resultados obtenidos y analizados, se ha demostrado en este proyecto, por tanto, que es posible hacer historia social de la educación en ciencias y de que esta es parte de la historia social de las ciencias. Para apoyar lo aseverado que la historia social de la educación en ciencias hace parte de la historia social de las ciencias, se trae a colación lo establecido por P. Kreimer (2009), en el sentido de que la admisión de una teoría o modelo científico no adquiere su aceptación e institucionalización definitiva, sino hasta cuando se incorpora a los textos de enseñanza de la ciencia correspondiente. Otro parecer es el análisis crítico de la transposición didáctica que de esa teoría o modelo se lleva a cabo. 
Historia social de la educación ...

La gran conclusión a la que llegaron los responsables de este proyecto de investigación, es la de que en Colombia, en la segunda mitad del siglo XX, no hubo específicamente una educación en ciencias que socializara entre la población escolar, una versión de la actividad científica y tecnológica como un componente indispensable del nuevo contexto cultural.

\section{Referencias}

AUSUBEL, D.; NOVAK, J.; HANESIAN, H. Psicología educativa: un punto de vista cognoscitivo. México: Trillas, 1983.

BARNES, B.; DOLBY, R. G. A. El ethos científico: un punto de vista divergente. In: IRANZO, J. M. et al. (Comp.). Sociología de la ciencia y la tecnología. Madrid: Consejo Superior de Investigaciones Científicas, 1995. p. 33-51.

BARONA, J. L. Ciencia e historia: debates y tendencias en la historiografía de la ciencia. Valencia: Guada, 1994.

BERNAL, J. Historia social de la ciencia: la ciencia de nuestro tiempo. Barcelona: Península, 1976. 2 v.

BOWLER, P. J.; MORUS, I. Panorama general de la ciencia moderna. Barcelona: Crítica, 2007.

CAMACHO GONZÁLEZ, J. P.; GALLEGO BADILLO, R.; PÉREZ MIRANDA, R. La ley periódica: un análisis histórico, epistemológico y didáctico de algunos textos de enseñanza. Educación Química, México, v. 18, n. 4, p. 278-288, 2007.

CHEVALLARD, Y. La transposition didactique: du savoir savant au savoir enseigné. Grenoble: La Pensée Sauvage, 1985.

COLLINS, H.; PINCH, T. El Gólem: lo que todos deberíamos saber acerca de la ciencia. Barcelona: Crítica: Grijalbo Mondadori, 2006.

CUELLAR FERNÁNDEZ, L. H.; GALLEGO BADILLO, R.; PÉREZ MIRANDA, R. El modelo atómico de E. Rutherford: del saber científico al conocimiento escolar. Enseñanza de las Ciencias, Barcelona, v. 26, n. 1, p. 43-52, 2008.

DERRY, T. K.; WILLIAMS, T. I. Historia de la tecnología: desde la antigüedad hasta 1750. México: Siglo XXI, 1977. v. 1.

DICKSON, D. Science and its public: the need for a "third way". Social Studies of Science, London, v. 30, n. 6, p. 917- 923, 2000. Disponible en: <http://www.jstor.org/ stable/285791>. Visitado en: 24 oct. 2013.

ECHEVARRÍA, J. Filosofía de las ciencias. Madrid: Akal, 1955.

ESTANY, A. El papel de la historia de la ciencia en los estudios interdisciplinares de la ciencia. In: MARTÍNEZ, S. F.; GUILLAUMIN, G. (Comp.). Historia, filosofía y enseñanza de la ciencia. México: UNAM, 2005. p. 291-303. 
Badillo, R. G. et al.

FRANCO, R. A. Aproximación a la historia social de la construcción de la comunidad científica en Colombia: 1950-1999. 2009. Trabajo de Grado (Graduación en Química) - Departamento de Química, Universidad Pedagógica Nacional, Bogotá, 2009.

GALLEGO BADILLO, R.; PÉREZ MIRANDA, R.; TORRES DE GALLEGO, L. N. Formación inicial de profesores de ciencias en Colombia: un estudio a partir de programas acreditados. Ciência \& Educação, Bauru, v. 10, n. 2, p. 219-234, 2004. Disponible en: <http://dx.doi.org/10.1590/S1516-73132004000200006>. Visitado en: 24 oct. 2013.

GALLEGO BADILLO, R. et al. La formación inicial de profesores de ciencias en Colombia: contrastación de fundamentos. Bogotá: Universidad Pedagógica Nacional, 2004. (Memoria de investigación).

. El papel de las "prácticas docentes" en la formación inicial de profesores de ciencias. Revista Electrónica de Enseñanza de las Ciencias, Vigo, v. 5, n. 3, p. 481-504, 2006. Disponible en: <http://reec.uvigo.es/volumenes/volumen5/ART6_Vol5_N3.pdf>. Visitado en: 24 oct. 2013.

GALLEGO TORRES, A. P. Contribución del cómic a la imagen de la ciencia. 2002. Tesis (Doctoral) - Departament de Didàctica de les Ciències Experimentals i Socials, Universitat de Valencia, Valencia, 2002.

GALLEGO TORRES, A. P.; MONTENEGRO MARÍN, C. E.; GALLEGO BADILLO, R. Reflexiones para una didáctica de las ingenierías. Revista Educación en Ingeniería, Bogotá, v. 7, n. 13, p. 83-90, 2012. Disponible en: <http://www.educacioneningenieria.org/ index.php/edi/article/view/30>. Visitado en: 24 oct. 2013.

GÁNDARA GOMEZ, M.; GIL QUÍLEZ, M. J.; SANMARTÍ PUIG, N. Del modelo científico de "adaptación biológica" al modelo de "adaptación biológica" en los libros de textos de enseñanza secundaria obligatoria. Enseñanza de las Ciencias, Barcelona, v. 20, n. 2, p. 303-314, 2002.

GENÉ, A. Cambio conceptual y metodológico en la enseñanza y el aprendizaje de la evolución de los seres vivos: un ejemplo concreto. Enseñanza de las Ciencias, Barcelona, v. 9, n. 1, p. 26-27, 1991.

GIL PEREZ, D.; CARRASCOSA ALIS, J. Science learning as a conceptual and methodological change. European Journal Science Education, Abingdon, v. 7, n. 3, p. 231-253, 1985. Disponible en: <http://dx.doi.org/10.1080/0140528850070302>. Visitado en: 30 oct. 2013.

JARAMILLO, R. Introducción de la filosofía moderna en Colombia. Argumentos, Bogotá, n. 14-17, p. 201-214, 1986.

JENKINS, K. ¿Por qué la historia? México: Fondo de Cultura Económica, 2006.

KNORR-CETINA, K. D. Los estudios etnográficos del trabajo científico: hacia una interpretación constructivista de la ciencia. In: In: IRANZO, J. M. et al. (Comp.). Sociología de la ciencia y la tecnología. Madrid: Consejo Superior de Investigaciones Científicas, 1995. p. 187-204. 
Historia social de la educación ...

KREIMER, P. El científico también es un ser humano: la ciencia bajo la lupa. Buenos Aires: Siglo Veintiuno, 2009.

KUHN, T. S. La estructura de las revoluciones científicas. México: Fondo de Cultura Económica, 1972.

LAKATOS, I. La metodología de los programas de investigación científica. Madrid: Alianza, 1983.

LATOUR, B.; WOOLGAR, S. La vida en el laboratorio: la construcción de los hechos científicos. Madrid: Alianza, 1995.

MATTHEWS, M. Science teaching: the role of history and philosophy of science. New York: Routledge, 1994.

MOREIRA, M. A. Pesquisa em ensino: o Ve epistemological de Gowin. Sao Paulo: E.P.U., 1990.

MULKAY, M. La visión sociológica habitual de la ciencia. In: IRANZO, J. M. et al. (Comp.). Sociología de la ciencia y la tecnología. Madrid: Consejo Superior de Investigaciones Científicas, 1995. p. 11-32.

MUMFORD, L. Técnica y civilización. Madrid: Alianza, 2006.

NOVAK, J. D. El constructivismo humano: un consenso emergente. Enseñanza de las Ciencias, Barcelona, v. 6, n. 3, p. 213-233, 1988.

NOVAK, J. D.; GOWIN, B. Learning how to learn. Cambridge: Cambridge University Press, 1984.

POPPER, K. La lógica de la investigación científica. Madrid: Tecnos, 1962.

POSNER, G. J. et al. Accommodation of a scientific conception: toward a theory of conceptual change. Science Education, Hoboken, v. 66, n. 2, p. 211- 227, 1982.

Disponible en: <http://dx.doi.org/10.1002/sce.3730660207>. Visitado en: 30 oct. 2013.

RESTIVO, S. La ciencia moderna como problema social. Fin de Siglo, Ciudad de Mexico, n. 3, p. 20-39, 1992.

SÁNCHEZ, J. M. El jardín de Newton: la ciencia a través de la historia. Barcelona: Crítica, 2009.

SHAPIN, S. Disciplina y delimitación: la historia y la sociología de la ciencia, a la luz del debate externismo-internismo. In: MARTÍNEZ, S. F.; GUILLAUMIN, G. (Comp.).

Historia, filosofía y enseñanza de la ciencia. México: UNAM, 2005. p. 67-119.

STENGER, I. La afinidad ambigua: el sueño newtoniano de la química del siglo XVIII. In: SERRES, M. (Ed.). Historia de las ciencias. Madrid: Cátedra, 1989. p. 317-361.

VESSURI, H. M. C. Perspectivas recientes en el estudio social de las ciencias. Fin de Siglo, Ciudad de Mexico, n. 3, p. 40-52, 1992. 
Badillo, R. G. et al.

WEIGHTMAN, G. Los revolucionarios industriales: la creación del mundo contemporáneo 1776-1914. Barcelona: Ariel, 2008.

ZAHAR, E. Experimentos cruciales: estudio de un ejemplo. In: ANDERSSON, G.;

RADNITZKY, G. (Ed.). Progreso y racionalidad en la ciencia. Madrid: Alianza, 1980. p. 70-94.

Artigo recebido em 23/01/13. Aceito em 20/10/13. 
Historia social de la educación ...

Anexo 1. Cuadros resumen de los resultados de las entrevistas.

Programa A UPN

Cuadro 5. Entrevista a director, profesores y egresados por año.

\begin{tabular}{|l|c|c|c|c|c|}
\hline & EC & HC & CT & TE & FP \\
\hline Dirct & PCr & $\mathrm{N}$ & $\mathrm{N}$ & $\mathrm{H}$ & $\mathrm{H}$ \\
\hline Prof1 & $\mathrm{H}$ & $\mathrm{N}$ & $\mathrm{N}$ & $\mathrm{H}$ & $\mathrm{H}$ \\
\hline Prof2 & $\mathrm{H}$ & $\mathrm{N}$ & $\mathrm{I}$ & $\mathrm{H}$ & $\mathrm{H}$ \\
\hline Prof3 & $\mathrm{H}$ & $\mathrm{N}$ & $\mathrm{I}$ & $\mathrm{H}$ & $\mathrm{NH}$ \\
\hline Egr59 & $\mathrm{H}$ & $\mathrm{N}$ & $\mathrm{N}$ & $\mathrm{H}$ & $\mathrm{H}$ \\
\hline Egr71 & $\mathrm{H}$ & $\mathrm{N}$ & $\mathrm{N}$ & $\mathrm{PCr}$ & $\mathrm{H}$ \\
\hline Egr72 & $\mathrm{H}$ & $\mathrm{N}$ & $\mathrm{N}$ & $\mathrm{H}$ & $\mathrm{H}$ \\
\hline Egr74 & $\mathrm{H}$ & $\mathrm{N}$ & $\mathrm{N}$ & $\mathrm{H}$ & $\mathrm{H}$ \\
\hline Egr68 & $\mathrm{H}$ & $\mathrm{N}$ & $\mathrm{N}$ & $\mathrm{H}$ & $\mathrm{H}$ \\
\hline Egr82 & $\mathrm{H}$ & $\mathrm{N}$ & $\mathrm{N}$ & $\mathrm{H}$ & $\mathrm{H}$ \\
\hline Egr86 & $\mathrm{H}$ & $\mathrm{N}$ & $\mathrm{N}$ & $\mathrm{H}$ & $\mathrm{H}$ \\
\hline Egr88 & $\mathrm{H}$ & $\mathrm{N}$ & $\mathrm{H}$ & $\mathrm{H}$ & $\mathrm{H}$ \\
\hline Egr88' & $\mathrm{H}$ & $\mathrm{N}$ & $\mathrm{N}$ & $\mathrm{PCr}$ & $\mathrm{PCr}$ \\
\hline Egr91 & $\mathrm{H}$ & $\mathrm{N}$ & $\mathrm{N}$ & $\mathrm{PCr}$ & $\mathrm{PCr}$ \\
\hline Egr93 & $\mathrm{H}$ & $\mathrm{N}$ & $\mathrm{N}$ & $\mathrm{PCr}$ & $\mathrm{H}$ \\
\hline Egr94 & $\mathrm{H}$ & $\mathrm{N}$ & $\mathrm{N}$ & $\mathrm{H}$ & $\mathrm{PCr}$ \\
\hline Egr94' & $\mathrm{H}$ & $\mathrm{N}$ & $\mathrm{I}$ & $\mathrm{H}$ & $\mathrm{H}$ \\
\hline
\end{tabular}

Fuente: elaborado por los autores.

\section{Programa B UPN}

Cuadro 6. Resultados entrevista a Director, Profesores y egresados por año.

\begin{tabular}{|l|c|c|c|c|c|}
\hline & EC & HC & CT & TE & FP \\
\hline Dirct & $\mathrm{H}$ & $\mathrm{NH}$ & $\mathrm{NH}$ & $\mathrm{NH}$ & $\mathrm{H}$ \\
\hline Prpf2 & $\mathrm{PCr}$ & $\mathrm{NH}$ & $\mathrm{N}$ & $\mathrm{H}$ & $\mathrm{H}$ \\
\hline Prof2 & $\mathrm{NH}$ & $\mathrm{NH}$ & $\mathrm{N}$ & $\mathrm{PCr}$ & $\mathrm{PCr}$ \\
\hline Prof3 & $\mathrm{H}$ & $\mathrm{H}$ & $\mathrm{H}$ & $\mathrm{H}$ & $\mathrm{H}$ \\
\hline Egr75 & $\mathrm{H}$ & $\mathrm{N}$ & $\mathrm{N}$ & $\mathrm{H}$ & $\mathrm{NH}$ \\
\hline Egr78 & $\mathrm{H}$ & $\mathrm{N}$ & $\mathrm{N}$ & $\mathrm{H}$ & $\mathrm{H}$ \\
\hline Egr84 & $\mathrm{H}$ & $\mathrm{H}$ & $\mathrm{N}$ & $\mathrm{H}$ & $\mathrm{H}$ \\
\hline Egr89 & $\mathrm{H}$ & $\mathrm{NH}$ & $\mathrm{N}$ & $\mathrm{H}$ & $\mathrm{H}$ \\
\hline
\end{tabular}

Fuente: elaborado por los autores. 
Badillo, R. G. et al.

\section{Programa C de la UPN}

Cuadro 7. Resultados entrevistas a director, profesores y egresados por año.

\begin{tabular}{|l|c|c|c|c|c|}
\hline & EC & HC & CT & TE & FP \\
\hline Dirct & $\mathrm{NH}$ & $\mathrm{NH}$ & $\mathrm{NH}$ & $\mathrm{PCr}$ & $\mathrm{NH}$ \\
\hline Prof1 & $\mathrm{NH}$ & $\mathrm{NH}$ & $\mathrm{NH}$ & $\mathrm{H}$ & $\mathrm{NH}$ \\
\hline Prof2 & $\mathrm{NH}$ & $\mathrm{N}$ & $\mathrm{N}$ & $\mathrm{H}$ & $\mathrm{H}$ \\
\hline Egr75 & $\mathrm{H}$ & $\mathrm{N}$ & $\mathrm{H}$ & $\mathrm{H}$ & $\mathrm{H}$ \\
\hline Egr75, & $\mathrm{H}$ & $\mathrm{H}$ & $\mathrm{N}$ & $\mathrm{H}$ & $\mathrm{PCr}$ \\
\hline Egr81 & $\mathrm{H}$ & $\mathrm{N}$ & $\mathrm{N}$ & $\mathrm{N}$ & $\mathrm{H}$ \\
\hline Egr87 & $\mathrm{H}$ & $\mathrm{H}$ & $\mathrm{N}$ & $\mathrm{H}$ & $\mathrm{H}$ \\
\hline Egr89 & $\mathrm{H}$ & $\mathrm{NH}$ & $\mathrm{N}$ & $\mathrm{H}$ & $\mathrm{NH}$ \\
\hline Egr97 & $\mathrm{H}$ & $\mathrm{H}$ & $\mathrm{N}$ & $\mathrm{H}$ & $\mathrm{H}$ \\
\hline
\end{tabular}

Fuente: elaborado por los autores.

\section{Facultad de Educación UTCH}

Cuadro 8. Resultados entrevistas a director, profesores y egresados por año.

\begin{tabular}{|l|c|c|c|c|c|}
\hline & EC & HC & CT & TE & FP \\
\hline DirctA & $\mathrm{H}$ & $\mathrm{N}$ & $\mathrm{I}$ & $\mathrm{NH}$ & $\mathrm{NH}$ \\
\hline DirctB & $\mathrm{H}$ & $\mathrm{N}$ & $\mathrm{N}$ & $\mathrm{H}$ & $\mathrm{PCr}$ \\
\hline Profs & $\mathrm{H}$ & $\mathrm{N}$ & $\mathrm{I}$ & $\mathrm{NH}$ & $\mathrm{NH}$ \\
\hline Egr84 & $\mathrm{H}$ & $\mathrm{N}$ & $\mathrm{I}$ & $\mathrm{H}$ & $\mathrm{H}$ \\
\hline Egr93 & $\mathrm{H}$ & $\mathrm{N}$ & $\mathrm{I}$ & $\mathrm{H}$ & $\mathrm{H}$ \\
\hline Egr93' & $\mathrm{H}$ & $\mathrm{N}$ & $\mathrm{I}$ & $\mathrm{H}$ & $\mathrm{PCr}$ \\
\hline Egr95 & $\mathrm{H}$ & $\mathrm{N}$ & $\mathrm{I}$ & $\mathrm{H}$ & $\mathrm{H}$ \\
\hline Egr97 & $\mathrm{H}$ & $\mathrm{N}$ & $\mathrm{I}$ & $\mathrm{H}$ & $\mathrm{H}$ \\
\hline
\end{tabular}

Fuente: elaborado por los autores.

\section{Universidad del Atlántico Programas A y B}

Cuadro 9. Resultados entrevistas a director, profesores y egresados por año.

\begin{tabular}{|l|c|c|c|c|c|}
\hline & EC & HC & CT & TE & FP \\
\hline DirctA & H & N & N & H & H \\
\hline DirctB & H & N & N & H & H \\
\hline Profs & $\mathrm{NH}$ & $\mathrm{N}$ & $\mathrm{N}$ & $\mathrm{H}$ & $\mathrm{H}$ \\
\hline Egrs & $\mathrm{PCr}$ & $\mathrm{N}$ & $\mathrm{N}$ & $\mathrm{H}$ & $\mathrm{H}$ \\
\hline
\end{tabular}

Fuente: elaborado por los autores. 
Historia social de la educación ...

Programa A UDFJC

Cuadro 10. Resultados entrevistas a director, profesores y egresados por año.

\begin{tabular}{|l|c|c|c|c|c|}
\hline & EC & HC & CT & TE & FP \\
\hline Dirct & H & N & H & H & H \\
\hline Prof1 & H & N & N & H & H \\
\hline Prof2 & H & N & N & H & H \\
\hline Egr80 & H & N & N & H & H \\
\hline Egr88 & H & N & N & H & H \\
\hline Egr98 & H & N & N & H & H \\
\hline
\end{tabular}

Fuente: elaborado por los autores.

\section{Programa B. UDFJC}

Cuadro 11. Resultados entrevistas a director, profesores y egresados por año.

\begin{tabular}{|l|c|c|c|c|c|}
\hline & EC & HC & CT & TE & FP \\
\hline Dirct & H & N & N & H & H \\
\hline Prof1 & H & N & I & H & H \\
\hline Prof2 & $\mathrm{H}$ & $\mathrm{N}$ & $\mathrm{I}$ & $\mathrm{H}$ & $\mathrm{H}$ \\
\hline Prof3 & $\mathrm{NH}$ & $\mathrm{NH}$ & $\mathrm{NH}$ & $\mathrm{H}$ & $\mathrm{PCr}$ \\
\hline Egr90 & $\mathrm{H}$ & $\mathrm{N}$ & $\mathrm{H}$ & $\mathrm{H}$ & $\mathrm{H}$ \\
\hline Egr96 & $\mathrm{H}$ & $\mathrm{N}$ & $\mathrm{N}$ & $\mathrm{H}$ & $\mathrm{H}$ \\
\hline Egr98 & $\mathrm{H}$ & $\mathrm{H}$ & $\mathrm{N}$ & $\mathrm{H}$ & $\mathrm{H}$ \\
\hline
\end{tabular}

Fuente: elaborado por los autores.

\section{Programa C UDFJC}

Cuadro 12. Resultados entrevistas a director, profesores y egresados por año.

\begin{tabular}{|l|c|c|c|c|c|}
\hline & EC & HC & CT & TE & FP \\
\hline Dirct & H & N & N & H & N \\
\hline Prof1 & H & H & H & H & H \\
\hline Prof2 & $\mathrm{H}$ & $\mathrm{N}$ & $\mathrm{N}$ & $\mathrm{H}$ & $\mathrm{H}$ \\
\hline Prof3 & $\mathrm{H}$ & $\mathrm{N}$ & $\mathrm{N}$ & $\mathrm{H}$ & $\mathrm{H}$ \\
\hline Egr83 & $\mathrm{H}$ & $\mathrm{N}$ & $\mathrm{N}$ & $\mathrm{H}$ & $\mathrm{H}$ \\
\hline Egr88 & $\mathrm{H}$ & $\mathrm{N}$ & $\mathrm{N}$ & $\mathrm{H}$ & $\mathrm{PCr}$ \\
\hline Egr90 & $\mathrm{H}$ & $\mathrm{N}$ & $\mathrm{N}$ & $\mathrm{H}$ & $\mathrm{H}$ \\
\hline
\end{tabular}

Fuente: elaborado por los autores. 
Badillo, R. G. et al.

\section{Programa A UNIVALLE}

Cuadro 13. Resultados entrevistas a director, profesores y egresados por año.

\begin{tabular}{|l|c|c|c|c|c|}
\hline & EC & HC & CT & TE & FP \\
\hline Dirct & H & N & N & H & H \\
\hline Profs & H & N & N & H & N \\
\hline Egr88 & H & N & N & H & PCr \\
\hline Egr90 & H & N & N & H & NH \\
\hline
\end{tabular}

Fuente: elaborado por los autores.

\section{Programa B UNIVALLE}

Cuadro 14. Resultados entrevistas a director, profesores y egresados por año.

\begin{tabular}{|l|c|c|c|c|c|}
\hline & EC & HC & CT & TE & FP \\
\hline Dirct & $\mathrm{H}$ & $\mathrm{Si}$ & $\mathrm{N}$ & $\mathrm{H}$ & $\mathrm{H}$ \\
\hline Profs & $\mathrm{H}$ & $\mathrm{N}$ & $\mathrm{N}$ & $\mathrm{H}$ & $\mathrm{H}$ \\
\hline Egr73 & $\mathrm{H}$ & $\mathrm{N}$ & $\mathrm{N}$ & $\mathrm{H}$ & $\mathrm{PCr}$ \\
\hline Egr82 & $\mathrm{H}$ & $\mathrm{N}$ & $\mathrm{N}$ & $\mathrm{H}$ & $\mathrm{H}$ \\
\hline Egr93 & $\mathrm{H}$ & $\mathrm{N}$ & $\mathrm{N}$ & $\mathrm{H}$ & $\mathrm{H}$ \\
\hline Egr95 & $\mathrm{H}$ & $\mathrm{N}$ & $\mathrm{I}$ & $\mathrm{H}$ & $\mathrm{H}$ \\
\hline Egr95' & $\mathrm{H}$ & $\mathrm{N}$ & $\mathrm{N}$ & $\mathrm{H}$ & $\mathrm{H}$ \\
\hline
\end{tabular}

Fuente: elaborado por los autores.

\section{Programa UNICAUCA}

Cuadro 15. Resultados entrevistas a director, profesores y egresados por año.

\begin{tabular}{|l|c|c|c|c|c|}
\hline & EC & HC & CT & TE & FP \\
\hline Dirct & H & N & N & - & - \\
\hline Prof1 & H & N & N & H & H \\
\hline Prof2 & H & $\mathrm{N}$ & $\mathrm{N}$ & $\mathrm{H}$ & $\mathrm{N}$ \\
\hline Egr75 & $\mathrm{H}$ & $\mathrm{N}$ & $\mathrm{N}$ & $\mathrm{H}$ & $\mathrm{H}$ \\
\hline Egr96 & $\mathrm{H}$ & $\mathrm{N}$ & $\mathrm{N}$ & $\mathrm{H}$ & $\mathrm{H}$ \\
\hline Egr98 & $\mathrm{H}$ & $\mathrm{N}$ & $\mathrm{N}$ & $\mathrm{N}$ & $\mathrm{PCr}$ \\
\hline Egr2000 & $\mathrm{H}$ & $\mathrm{N}$ & $\mathrm{N}$ & $\mathrm{H}$ & $\mathrm{H}$ \\
\hline
\end{tabular}

Fuente: elaborado por los autores. 